\title{
Nurse accuracy in interpreting pH from pH strip testing
}

\author{
R. J. Clemente \\ Department of Nutrition and Dietetics, Frenchay Hospital, Bristol, UK
}

\begin{abstract}
In 2004, the medical device agency advised that nasogastric tube (NGT) position should be confirmed using pH sticks or papers ${ }^{(1)}$. However, $\mathrm{pH}$ strips and sticks have limited evidence for validity or reliability. This study determines nurses' accuracy in assessing $\mathrm{pH}$ of a series of solutions using $\mathrm{pH}$ strips. Particularly, the identification of $\mathrm{pH} 5.5$ or 6 in accordance with the thresholds used in current national guidance $^{(2,3)}$ on identifying NGT position. Nine buffered solutions of $\mathrm{pH} 3-7$ rising in 0.5 increments were produced by the biochemistry department and randomly assigned to 1 of 34 pots. Half of the sample had a $\mathrm{pH} \leq 5.5$ with double blinding to both participants and researcher. Ten nurses were asked to measure and record the $\mathrm{pH}$ of the solutions using a Merck 2-9 strip. Nurses were incorrect in $30 \%$ of $\mathrm{pH}$ measurements. At $\mathrm{pH} 6,12 \%$ of the sample were identified as having a pH 5.5. The reliability and validity of the strip was good as confirmed by KAPPA; however, specificity and sensitivity was poor at $\mathrm{pH} 6(64.7 \%)$ but better at $\mathrm{pH} 5.5(88 \%)$, as determined by a receiver operator characteristic (ROC) curve. In this study, use of $\mathrm{pH}$ sticks to determine a pH threshold of 5.5 means $12 \%$ of $\mathrm{pH} 6$ measurements will be misclassified as gastric when they could be respiratory. Adoption of a gastric $\mathrm{pH}$ threshold of $\leq 5.0$ would have prevented any theoretically mal-positioned tubes being used.
\end{abstract}

1. Medical Device Alert (2004) Enteral feeding tubes (nasogastric) MDA/2004/026, MHRA Notice MHRS/MS/2004/026.

2. National Institute for Health and Clinical Excellence (NICE) (2006) Nutrition Support in Adults. Clinical Guideline 32.

3. National Patient Safety Agency (2005) Patient Safety Alert 05: Reducing the Harm Caused by Misplaced Nasogastric Feeding Tubes. 